\title{
Effect of Home Based Yoga on Blood Pressure and Quality of Life in Patients with Hypertension
}

\author{
Shweta Parikh ${ }^{1}$, Priyanka Mahida ${ }^{1}$, Nirav Vaghela' ${ }^{1}$ Hasmukh Shah ${ }^{2, *}$
}

\section{Shweta Parikh¹, Priyanka Mahida', Nirav Vaghela', Hasmukh Shah',* 'Department of Physiotherapy, KMPIP, Bhaikaka University, Karamsad, Gujarat, INDIA. \\ 2Department of Physiology, Pramukhswami Medical College \& Bhaikaka University, , Karamsad, Gujarat, INDIA. \\ *Correspondence \\ Dr. Hasmukh D. Shah \\ Professor and Head, Department of Physiology, Pramukhswami Medical College, Bhaikaka University, Karamsad, Gujarat-388 325, INDIA. \\ Phone: + 919879731388 \\ Email: drhasmukhshah0505@gmail. com}

\section{History}

- Submission Date: 17-02-2021;

- Review completed: 19-03-2021;

- Accepted Date: 27-03-2021.

DOI : 10.5530/ijcep.2021.8.1.7

Article Available online

http://www.ijcep.org

\section{Copyright}

(C) 2021 Phcog.Net. This is an openaccess article distributed under the terms of the Creative Commons Attribution 4.0 International license.

\begin{abstract}
Background and Aim: Hypertension is one of the major growing global problems Management of hypertension by medicine, diet and exercise is not enough and alternative therapy is need of time. Yoga is one such substitute healthcare practice assumed to improve blood pressure control and quality of life in hypertensive. A prospective intervention was designed to check the effect of home based yoga exercise on blood pressure and quality of life in hypertensives. Methods: A total 74 hypertensive participants were recruited for the present study after following inclusion and exclusion criteria. Participants were divided into two groups, study group ( $n=39$ ) who have done home based yoga and control group $(n=35)$ who have not done home based yoga. Detailed methodology of home based yoga; their advantage and disadvantage were explained to the study group very well. Study group have done their home based yoga for three months and control group did not have done the home based yoga. Cardiovascular parameters like systolic blood pressure, diastolic blood pressure and pulse rate were recorded after following all standard precautions at the time of initiation of study and at end of every month till completion of study. Participants were also assessed for their quality of life, health and other areas of life by World Health Organization Quality of Life questionnaire at the time of beginning of the study and at every month till completion of study. Results: Significant decrease in systolic blood pressure from $130.60 \pm 4.06$ to 124.20 $\pm 0.60 \mathrm{~mm}$ of $\mathrm{Hg}$ and diastolic blood pressure from $85.62 \pm 5.55$ to $79.21 \pm 0.73 \mathrm{~mm}$ of $\mathrm{Hg}$ were seen in study group. In control group, blood pressure reduction was not seen. Self rated score of quality of life was improved in study group as compared to control group. Conclusion: A short term home-based yoga program in hypertensive patients have shown to reduce blood pressure as well as positive effect on self-rated quality of life compared to controls. A simple 12-weeks duration home based yoga exercise program may be useful as supplementary therapy in addition to antihypertensive drugs in hypertensive patients.

Key words: Hypertension, Home based yoga exercise, Quality of life.
\end{abstract}

\section{INTRODUCTION}

Hypertension is prevalent in approximately 25$26 \%$ of world's population. ${ }^{[1]}$ The World Health Organization (WHO) has identified high blood pressure as one of the most important causes of premature morbidity and mortality in both developed and developing countries. ${ }^{[2]}$ Globally, approximately, 7.6 million deaths occurred per year due to hypertension. ${ }^{[3]}$ According to the World Health Organization (WHO) 2008 estimates, the prevalence of raised Blood Pressure in Indians was $32.5 \%$ (33.2\% in men and $31.7 \%$ in women). ${ }^{[4]}$ During last few decades, India witnessed process of rapid economic development and modernization with changing lifestyle factors leading to increasing trend of hypertension in both rural and urban area. ${ }^{[5,6]}$ Changing socioeconomic status and life style might play important role in development of hypertension. ${ }^{[6]}$ Physical inactivity due to usage of electronic gadgets might play a key role in development hypertension. Obesity, hypertension and diabetes mellitus are commonly seen in

persons with physical inactivity. Lack of physical activity account for poor control of hypertension and increased risk of cerebrovascular disease and ischemic heart disease in patients with uncontrolled hypertension. ${ }^{[7]}$ Uncontrolled hypertension is associated with increased burden on health-care system and on economy. A high rate of nonadherence with drugs is seen in uncontrolled hypertension. Alternative, simple, affordable individual therapy to reduce blood pressure may be adapted to positive lifestyle change.

Yoga is an alternative therapy for stress management and to reduce blood pressure. ${ }^{[8-10]}$ Yoga is ancient traditional methods practiced in India for good health and prevention of diseases since last 50008000 years. $^{[11-13]}$ Yoga consists of various posture (asana), breathing practices and meditation techniques (pranayamas) and the most important is yogic behavior. ${ }^{[14,15]}$ Nevertheless, it is an ancient system of self-development which deals with a holistic approach to a person through its belief

Cite this article: Parikh S, Mahida P, Vaghela N, Shah H. Effect of Home Based Yoga on Blood Pressure and Quality of Life in Patients with Hypertension. Int J Clin Exp Physiol. 2021;8(1):26-30. 
and practices; synchronizes the body and mind. ${ }^{[16]}$ Regular breathing practice reduces sympathetic activity, increases parasympathetic control along with improvement function of respiratory system, cardiovascular system, neuro-endocrine system. ${ }^{[17,18]}$ Yogic practices are helpful in autonomic control over visceral functions. Savasana practice is helpful in reducing stress and strain to body and mind and improves physical and mental health. ${ }^{[1,20]}$ It also improves quality of life and subjective wellbeing. Regular practice of yogasana makes individual more active and flexible, positive toward self and environment.

Yogic practices make individual physically active. Enhanced parasympathetic control and reduced sympathetic activity is seen yogic persons and which ultimately leads to good cardiovascular health. ${ }^{[21]}$ Approximately 4-6 mmHg reduction in systolic blood pressure (SBP) and diastolic blood pressure (DBP) after yoga practices was documented in few studies. Even small reduction in blood pressure after shorter duration of intervention play key role clinically. The reduction in blood pressure which could be the effect of yoga may be useful as an additional therapy in addition to medical treatment of hypertension.

The effect of home-based yoga on hypertension and the quality of life of hypertensive patients were not studied adequately in Indian population. Therefore, the present study was undertaken to see the impact of yoga in hypertensive patients and their quality of life.

\section{MATERIALS AND METHODS}

A randomized control trial was done on total 74 hypertensive participants after approval of Institution Ethics Committee at Pramukhswami Medical College, Karamsad. Participants were informed in detailed about methodology of study, benefits and risk associated with the study. Participants were enrolled voluntarily after their written informed consent.

\section{Inclusion and Exclusion Criteria}

Participants with uncontrolled hypertension i.e. SBP $\geq 180 \mathrm{mmHg}$ and $\mathrm{DBP} \geq 110 \mathrm{mmHg}$ were excluded from the study. Participants with history of other cardiovascular diseases, respiratory diseases were excluded from the study. Participants who were doing yoga regularly also excluded from the study.

\section{Grouping}

Participant's recruitment for study group was done by lottery system. Participants were divided into two groups, study group $(n=39)$ who have done home based yoga and control group $(n=35)$ who have not done home based yoga. Detailed methodology of home based yoga; their advantage and disadvantage were explained to the study group very well. Study group have done their home based yoga for three months and control group have not done the home based yoga along with their prescribed antihypertensive drugs.

\section{Parameters Assessed}

Cardiovascular parameters like SBP, DBP and pulse rate (PR) were recorded after following all standard precautions at the time of initiation of study and at end of every month till completion of study. Participants were also assessed for their quality of life, health and other areas of life by World Health Organization Quality of Life questionnaire (WHOQoLBREF) at the time of beginning of the study and at every month till completion of study. Regular follow up of study was done by regular phone calls at interval of 15 days. Assessment of blood pressure profile and quality of life were done at Physiotherapy Department regularly at the end of month for the next three months.

\section{Measurement of Blood Pressure}

The participants were asked to relax in sitting position for a period of 5 min. PR and BP were measured in the right upper extremity in sitting position with the arm supported on Table and back supported uncrossed legs and feet on the floor. PR, SBP and DBP were measured at the brachial artery from the right arm using the Omron T8 (HEM757A4-C1) Automatic Blood Pressure Instrument (Accuracy, BP: $\pm 4 \mathrm{~mm} \mathrm{Hg}$, Pulse: \pm 5 ), validated by Association for the Advancement of Medical Instrumentation, (AAMI) and British Hypertension Society, (BHS). ${ }^{[2]}$ Blood pressure and pulse rate were documented at every 1 min until the difference between two successive BP readings was less than $5 \mathrm{~mm} \mathrm{Hg}$. Pulse pressure (PP) and Mean arterial pressure (MAP) were calculated from the average values of SBP and DBP using the formula $\mathrm{PP}=\mathrm{SBP}-$ $\mathrm{DBP}$ and $\mathrm{MAP}=\mathrm{DBP}+1 / 3(\mathrm{PP})$ respectively.

\section{Assessment of QoL}

The WHOQOL-BREF questionnaire is a shorter version of the WHOQOL-100, containing 26 items which reflect QOL. The 26 items were divided into four domains: Physical health with 7 items (DOM1), Psychological health with 6 items (DOM2), Social relationships with 3 items (DOM3) and Environmental health with 8 items (DOM4). There are also two items that are analyzed separately: overall perception of quality of life and overall perception of health. The participants were given the questioners in vernacular language and were asked to fill it.

\section{Home Based Yoga}

Participants in the study group were taught for three different types of yoga for total $20 \mathrm{~min}$ of duration before the beginning of the study. The yoga module includes left nostril breathing for $10 \mathrm{~min}$, savasana for 5 min and followed by spinal reflex for $5 \mathrm{~min}$. Left nostril breathing which includes deep breathe-in and breathe-out through the left nostril while sitting or lying down, with the right nostril closed off by the right thumb or an earplug. ${ }^{[23-25]}$ Savasana (Relaxation posture) means lie down in the supine posture for $5 \mathrm{~min}$ during which participants are supposed to do self relaxation. Spinal flex means movement that alternates between flexing the spine forwards (arching) and relaxing the spine back in time with deep breaths while sitting in a chair for about 5 min. Participants were informed to do home based yoga regularly at their home.

\section{Statistical Analysis of Data}

Descriptive analysis was used for characteristics of participants and to calculate frequency, mean and standard deviation. Paired sample $t$ test was used to compare the difference of pre and post intervention values of blood pressure parameters and quality of life in between study and control group. Independent $t$ test was used to compare the differences between two groups for same outcome measures. Probability values less than 0.05 were considered statistically significant.

\section{RESULTS}

Baseline characteristics of study and control group were shown in Table 1. There was no significant difference in the characteristics of the participants between two groups with regards to age, body mass index, SBP, DBP, PR, PP, MAP and QOL.

Blood pressure profile of participants of study group and control group were shown in Table 2. There was no significant difference in SBP, DBP, PR and MAP in study group and control group. Improvement in systolic blood pressure and diastolic blood pressure was seen in study group who performed home based yoga exercise at 1 month, 2 month and 3 months. Systolic and diastolic blood pressure was remained static in control group at the end of each month. Improvement in SBP for yoga at home group was significantly greater than that for the control group $(-6.4 \pm 2.76 \mathrm{vs}$ 
$0.58 \pm 1.24 \mathrm{mmHg} ; \mathrm{P}<0.05)$. Similarly improvement in DBP for yoga at home group was significantly more than that for the control group (-6.41 \pm 2.70 vs $0.64 \pm 1.68 \mathrm{mmHg} ; \mathrm{P}<0.05)$.

As per Table 3, various domains of self-rated quality of life (WHOQoL) like, physical health (domain 1), psychological health (domain 2), social relationship (domain 3) and environmental health (domain4) remained static in control group after first, second and third month of the study. The yoga at home group showed significant improvements in self-rated quality of life compared to the control group $(10.69 \pm 4.34$ vs $-0.42 \pm 3.66$; $\mathrm{P}<0.05)$ after first, second and third months. A statistically significant improvement in physical health and psychological health was seen in

Table 1: Baseline characteristics of the participants.

$\begin{array}{cccc}\text { Variables } & \begin{array}{c}\text { Study Group } \\ (\mathrm{n}=39)\end{array} & \begin{array}{c}\text { Control Group } \\ (\mathrm{n}=35)\end{array} & \mathrm{P} \\ \text { Age } & 57.41 \pm 8.14 & 58.54 \pm 8.67 & 0.5643 \\ \text { BMI } & 27.32 \pm 4.62 & 26.72 \pm 3.59 & 0.5388 \\ \text { Pulse Rate (PR) } & 86.15 \pm 5.51 & 85.87 \pm 5.07 & 0.8201 \\ \text { SBP } & 130.60 \pm 4.06 & 130.80 \pm 4.28 & 0.8392 \\ \text { DBP } & 85.62 \pm 5.55 & 84.63 \pm 5.69 & 0.4536 \\ \text { PP } & 45.77 \pm 6.75 & 46.16 \pm 5.39 & 0.7868 \\ \text { MAP } & 100.87 \pm 4.63 & 100.01 \pm 4.60 & 0.4292 \\ \text { Quality Of Life } & 82.25 \pm 9.40 & 79.71 \pm 7.25 & 0.2010 \\ \text { (QOL) } & & & \end{array}$

$P$ value less than 0.05 was considered to be statistically significant

Table 2: Blood Pressure parameters on various months of study group and control group.

\begin{tabular}{|c|c|c|c|c|}
\hline & & $\begin{array}{l}\text { Study Group } \\
\qquad(n=39)\end{array}$ & $\begin{array}{l}\text { Control } \\
\text { Group } \\
(n=35)\end{array}$ & $\mathbf{P}$ \\
\hline \multirow{4}{*}{$\begin{array}{c}\text { SBP } \\
(\mathrm{mmHg})\end{array}$} & Before the study & $130.60 \pm 4.06$ & $130.80 \pm 4.28$ & 0.8392 \\
\hline & Post 1 month & $128.6 \pm 0.62$ & $131.3 \pm 0.66$ & 0.034 \\
\hline & Post 2 month & $126.3 \pm 0.60$ & $131.4 \pm 0.66$ & 0.0001 \\
\hline & Post 3 month & $124.2 \pm 0.60$ & $131.4 \pm 0.67$ & 0.0001 \\
\hline \multirow{4}{*}{$\begin{array}{c}\mathrm{DBP} \\
(\mathrm{mmHg})\end{array}$} & Before the study & $85.62 \pm 5.55$ & $84.63 \pm 5.69$ & 0.4536 \\
\hline & Post 1 month & $83.46 \pm 0.81$ & $85.33 \pm 0.88$ & 0.1257 \\
\hline & Post 2 month & $81.35 \pm 0.78$ & $85.34 \pm 0.86$ & 0.0011 \\
\hline & Post 3 month & $79.21 \pm 0.73$ & $85.28 \pm 0.91$ & 0.0001 \\
\hline \multirow{4}{*}{ PR } & Before the study & $86.15 \pm 5.51$ & $85.87 \pm 5.07$ & 0.8201 \\
\hline & Post 1 month & $83.21 \pm 0.78$ & $86.41 \pm 0.77$ & 0.0052 \\
\hline & Post 2 month & $81.44 \pm 0.79$ & $86.46 \pm 0.76$ & 0.0001 \\
\hline & Post 3 month & $79.26 \pm 0.70$ & $86.29 \pm 0.76$ & 0.0001 \\
\hline \multirow{4}{*}{ MAP } & Before the study & $100.87 \pm 4.63$ & $100.01 \pm 4.60$ & 0.4292 \\
\hline & Post 1 month & $98.45 \pm 0.64$ & $100.6 \pm 0.70$ & 0.0252 \\
\hline & Post 2 month & $96.33 \pm 0.63$ & $100.8 \pm 0.69$ & 0.0001 \\
\hline & Post 3 month & $94.24 \pm 0.61$ & $100.6 \pm 0.71$ & 0.0001 \\
\hline
\end{tabular}

$\mathrm{P}$ value less than 0.05 was considered to be statistically significant.

SBP: Systolic blood pressure; DBP: Diastolic blood pressure; PP: Pulse pressure; MAP: Mean arterial pressure;
Table 3: QOL and its domains on various months of study group and control group.

\begin{tabular}{|c|c|c|c|c|}
\hline & & $\begin{array}{l}\text { Study Group } \\
\qquad(n=39)\end{array}$ & $\begin{array}{l}\text { Control Group } \\
\qquad(n=35)\end{array}$ & $P$ \\
\hline \multirow{4}{*}{ QoL } & $\begin{array}{l}\text { Before the } \\
\text { study }\end{array}$ & $82.25 \pm 9.40$ & $79.71 \pm 7.25$ & 0.2010 \\
\hline & Post 1 month & $84.56 \pm 1.32$ & $79.63 \pm 1.25$ & 0.0090 \\
\hline & Post 2 month & $88.54 \pm 1.35$ & $79.46 \pm 1.26$ & 0.0001 \\
\hline & Post 3 month & $92.95 \pm 1.15$ & $79.29 \pm 1.31$ & 0.0001 \\
\hline \multirow{4}{*}{$\begin{array}{c}\text { QoL } \\
\text { Domain } 1\end{array}$} & $\begin{array}{l}\text { Before the } \\
\text { study }\end{array}$ & $22.20 \pm 4.20$ & $21.31 \pm 3.52$ & 0.329 \\
\hline & Post 1 month & $23.46 \pm 3.85$ & $21.28 \pm 3.54$ & 0.014 \\
\hline & Post 2 month & $25.28 \pm 3.81$ & $21.14 \pm 3.49$ & 0.0001 \\
\hline & Post 3 month & $27.28 \pm 3.37$ & $21.02 \pm 3.72$ & 0.0001 \\
\hline \multirow{4}{*}{$\begin{array}{c}\text { QoL } \\
\text { Domain } 2\end{array}$} & $\begin{array}{l}\text { Before the } \\
\text { study }\end{array}$ & $19.45 \pm 3.11$ & $18.28 \pm 2.69$ & 0.0895 \\
\hline & Post 1 month & $20.10 \pm 2.68$ & $17.85 \pm 3.05$ & 0.0012 \\
\hline & Post 2 month & $21.97 \pm 3.02$ & $17.82 \pm 3.12$ & 0.0001 \\
\hline & Post 3 month & $24.15 \pm 3.24$ & $17.82 \pm 3.03$ & 0.0001 \\
\hline \multirow{4}{*}{$\begin{array}{c}\text { QoL } \\
\text { Domain } 3\end{array}$} & $\begin{array}{l}\text { Before the } \\
\text { study }\end{array}$ & $12.71 \pm 0.97$ & $12.77 \pm 0.84$ & 0.778 \\
\hline & Post 1 month & $12.82 \pm 0.94$ & $12.57 \pm 1.03$ & 0.2826 \\
\hline & Post 2 month & $13.00 \pm 0.97$ & $12.57 \pm 1.03$ & 0.0709 \\
\hline & Post 3 month & $13.23 \pm 0.95$ & $12.57 \pm 1.03$ & 0.0058 \\
\hline \multirow{4}{*}{$\begin{array}{c}\text { QoL } \\
\text { Domain } 4\end{array}$} & $\begin{array}{l}\text { Before the } \\
\text { study }\end{array}$ & $27.97 \pm 2.76$ & $27.28 \pm 1.58$ & 0.690 \\
\hline & Post 1 month & $27.89 \pm 2.74$ & $27.4 \pm 1.70$ & 0.3580 \\
\hline & Post 2 month & $28.30 \pm 2.81$ & $27.4 \pm 1.70$ & 0.1019 \\
\hline & Post 3 month & $28.61 \pm 2.85$ & $27.37 \pm 1.71$ & 0.0281 \\
\hline
\end{tabular}

$P$ value less than 0.05 was considered to be statistically significant. QOL: Quality of Life.

study group, but no change in social relationship and environmental health was seen in study group at first, second and third months of the study.

\section{DISCUSSION}

Effect of home based yoga exercise on blood pressure and quality of life in rural tertiary care centre was done in adult Indian hypertensive. The present study showed significant reduction in systolic, diastolic and mean blood pressure in participants who practiced yoga exercise at home for the duration of three months as compared to control group $(\mathrm{P}<0.05)$. Participants who performed yoga at home showed greater improvement in quality of life than control group $(\mathrm{P}<0.05)$. The results of present study show that home based yoga exercise may be useful as an additional tool for treatment of hypertension. Though present study was conducted at tertiary care centre, a simple yogic exercise of short duration which is easily to perform at home and considered one of the best alternative and complementary therapy for treatment of hypertension.

Raghuraj P (2008) documented reduction in systolic and mean arterial blood pressure with alternate nostril yoga breathing. ${ }^{[26]}$ Khanam et al. reported that yogic exercise involves physical, mental and spiritual task in a comprehensive manner and brings behavioral change. ${ }^{[27]}$ Guleria $\mathrm{R}$, Deepak K. showed decrease in systolic and diastolic blood pressure through its impact on vasomotor centre which leads to declining in 
sympathetic tone and peripheral resistance. ${ }^{[27]}$ Moa Wolff (2013) showed home based yoga for reduction on blood pressure and improvement in quality of life in hypertensive participants as compared to classroom yoga. ${ }^{[28]}$ Results of our study were also supported by Jain $S$, et al. and Hegde SV, et al. documented usefulness of even small reductions in blood pressure to reduce risk of coronary artery disease and stroke. ${ }^{[29,30]}$ Chobanian AV (2003) reported role of yogic interventions for reduction of blood pressure by postures, meditation and breathing. ${ }^{[31]}$ The Savasana, a relaxation exercise probably influences the hypothalamus through the continuous feedback of slow rhythmic proprioceptive and interoreceptive impulses ${ }^{[32]}$ that can establish a psycho-physiological relaxation and reduce the physiological stress in a shorter time. ${ }^{[33]}$ Udupa $\mathrm{KN}^{[14]}$ and Wood $\mathrm{C}^{[15]}$ have reported the beneficial effects of 'Hatha Yoga' on psychological well-being and improvement in quality of life. Desharnais R (1993) have mentioned the psychological benefits of an aerobic exercise program. ${ }^{[34]}$ Malathi A have reported role of regular yogic practices in improvement of subjective wellbeing. ${ }^{[35]}$

Strength of this research study includes its easy applicability by end user. Home based yoga exercises are taught to participants with ease within very short time by physician. Home based yoga exercises are easy to perform by participants at their home as per their convenience. Significant reduction in blood pressure and improvement in quality of life by home based yogic exercises is useful to reduce morbidity and mortality associated with hypertension and advised as an alternative supplementary therapy to patients of metabolic diseases. The main limitations of our study include that the study was performed at single institution with small number of participants. Regular performance of yogic exercise at home by participants is itself one of the biggest limitations as we have to rely or to trust on our participants. Recruitment of participants was done by lottery system and authors were unable to recruit all participants considered as a limiting step.

\section{CONCLUSION}

In our randomized control trial, patients with hypertension showed marked reduction in their blood pressure and improvement in quality of life after 3 months home based yogic exercise. Prescription of home based yoga exercises may be useful as an additional antihypertensive therapy along with medical treatment by tertiary care physicians. Larger cohort is helpful to reduce compliance and cost of antihypertensive treatment. Larger randomized control trail for longer duration is needed to study antihypertensive effects of yoga and to check positive effects on quality of life.

\section{ACKNOWLEDGEMENT}

The authors are grateful to our parent organization Charutar Arogya Mandal, Karamsad, for providing a platform for the study. The authors are obliged to our participants without them this study was not possible.

\section{CONFLICT OF INTEREST}

The authors declare that they have no conflict of interest.

\section{ABBREVIATIONS}

WHO: World Health Organization; SBP: Systolic Blood Pressure; DBP: Diastolic Blood Pressure; WHOQoL-BREF: World Health Organization Quality Of Life Questionnaire; PR: Pulse Rate; PP: Pulse Pressure; MAP: Mean Arterial Pressure.

\section{REFERENCES}

1. Kearney PM, Whelton M, Reynolds K, Muntner P, Whelton PK, He J. Global burden of hypertension: Analysis of worldwide data. Lancet. 2005;365:217-
223

2. Khairnar G, Naik J, Mokale V. A statistical study on the development of micro particulate sustained drug delivery system for Losartan potassium by 32 factorial design approach. Bull Fac Pharm Cairo Univ. 2017;55(1):19-29.

3. Arima H, Barzi F, Chalmers J. Mortality patterns in hypertension. J Hypertens. 2011;29:S3-7.

4. Anchala $\mathrm{R}$, Kannuri NK, Pant $\mathrm{H}$, Khan $\mathrm{H}$, Franco $\mathrm{OH}$, Angelantonio $\mathrm{E}$, et al. Hypertension in India: A systematic review and meta-analysis of prevalence, awareness, and control of hypertension. J Hypertens. 2014;23(6):1170-7.

5. Gupta R. Trends in hypertension epidemiology in India. J Human Hypertens. 2004;18(2):73-8.

6. Tyagi R, Kapoor S. Ageing in structural and functional dimensions among institutionalized and non-institutionalized senior citizens. Anthropologie. 2004;42(2):141-6.

7. Rodgers A, Carlene L, MacMahon S. Reducing the global burden of blood pressure-related cardiovascular disease. J Hypertens. 2000;18(1):S3

8. Okonta NR. Does yoga therapy reduce blood pressure in patients with hypertension? An integrative review. Holist Nurs Pract. 2012;26(3):137-41.

9. Innes KE, Heather KV. The influence of yoga-based programs on risk profiles in adults with type 2 diabetes mellitus: A systematic review. Evid Based Complement Alternat Med. 2007;4(4):469-86.

10. Innes KE, Cheryl B, Ann GT. Risk indices associated with the insulin resistance syndrome, cardiovascular disease, and possible protection with yoga: A systematic review. J Am Board Family Pract. 2005;18(6):491-519.

11. Walters JD, Swami K. The art and science of Raja Yoga: Fourteen steps to higher awareness: Based on the teachings of Paramhansa Yogananda. Crystal Clarity Publishers; 2002.

12. Feuerstein G. The Yoga Tradition: Its History, Literature, Philosophy, and Practice, Bhavana Books, New Delhi, India; 2002.

13. Brown RP, Gerbarg PL. Sudarshan Kriya Yogic breathing in the treatment of stress, anxiety, and depression: Part $\|$-clinical applications and guidelines. $J$ Altern Complement Med. 2005;11(4):711-7.

14. Baldwin MC. Psychological and Physiological Influences of Hatha Yoga Training on Health, Exercising Adults. Medicine. 1999

15. Cowen VS, Adams TB. Physical and perceptual benefits of yoga asana practice: Results of a pilot study. J Bodywork Movem Ther. 2005;9(3):211-9.

16. Nayak NN, Shankar K. Yoga: A therapeutic approach. Physic Med Rehab Clin 2004;15(4):783-98.

17. Satyanand V, Reddy B, Mahaboobvali S, Mohanan D, Salma S, Nuzhath FJ. Effect of yoga on hypertension. Narayana Med J. 2016;5:5-11.

18. Patel C. Reduction of serum cholesterol and blood pressure in hypertensive patients by behaviour modification. The Journal of the Royal College of General Practitioners. 1976;26(164):211-5.

19. Chaudhary AK, Bhatnagar HN, Bhatnagar LK, Chaudary K. Comparative study of the effect of drugs and relaxation exercise (yoga shavasan) in hypertension. J Assoc Physicians India. 1988;36(12):721.

20. Mogra AL, Singh G. Effect of biofeedback and yogic relaxation exercise on the blood pressure levels of hypertensives: A preliminary study. Aviat Med. 1986;30:68-75.

21. Barnes VA, Treiber FA, Turner JR, Davis $H$, Strong WB. Acute effects of transcendental meditation on hemodynamic functioning in middle-aged adults. Psychosom Med. 1999;61(4):525

22. Shaikh WA, Patel M, Singh SK. Association of sleep duration with arterial blood pressure profile of Gujarati Indian adolescents. Indian J Community Med. 2010;35(1):125.

23. Satyanand V, Reddy B, Mahaboobvali S, Mohanan D, Salma S, Nuzhath FJ. Effect of yoga on hypertension. Narayana Med J. 2016;5:5-11.

24. Oken BS, Zajdel D, Kishiyama S, Flegal K, Dehen C, Haas M, et al. Randomized, controlled, six-month trial of yoga in healthy seniors: effects on cognition and quality of life. Altern Ther Health Med. 2006;12(1):40.

25. Wolff M, Sundquist K, Lonn SL, Midlov P. Impact of yoga on blood pressure and quality of life in patients with hypertension-a controlled trial in primary care, matched for systolic blood pressure. BMC Cardiovasc Disord. 2013;13(1):111.

26. Raghuraj P, Telles S. Immediate effect of specific nostril manipulating yoga breathing practices on autonomic and respiratory variables. Appl Pychophysiol Biofeedback. 2008;33(2):65-75.

27. Guleria R, Deepak KK. Study of pulmonary and autonomic functions of asthma patients after yoga training. Indian J Physiol Pharmacol. 1996;40(4):318-24

28. Wolff M, Sundquist K, Lonn SL, Midlov P. Impact of yoga on blood pressure and quality of life in patients with hypertension-a controlled trial in primary care, matched for systolic blood pressure. BMC Cardiovasc Disord. 2013;13(1):111

29. Jain S, Jain M, Sharma CS. Effect of yoga and relaxation techniques on cardiovascular system. Indian J Physiol Pharmacol. 2010;54(2):183-5

30. Hegde SV, Adhikari P, Kotian S, Pinto VJ, D'Souza S, D'Souza V. Effect of 3-month yoga on oxidative stress in type 2 diabetes with or without complications: A controlled clinical trial. Diab Care. 2011;34(10):2208-10.

31. Chobanian AV, Bakris GL, Black HR, Cushman WC, Green LA, Izzo JL, et al. 
The seventh report of the joint national committee on prevention, detection, evaluation, and treatment of high blood pressure: The JNC 7 report. JAMA. 2003;289(19):2560-71.

32. Whelton PK, He J, Appel LJ, Cutler JA, Havas S, Kotchen TA, et al. Primary prevention of hypertension: Clinical and public health advisory from The National High Blood Pressure Education Program. JAMA. 2002;288(15):1882-8.

33. Schneider RH, Staggers F, Alexander CN, Sheppard W, Rainforth M, Kondwani
$\mathrm{K}$, et al. A randomized controlled trial of stress reduction for hypertension in older African Americans. Hypertension. 1995;26(5):820-7.

34. Desharnais R, Jobin J, Cote C, Levesque L, Godin G. Aerobic exercise and the placebo effect: A controlled study. Psychosom Med. 1993;55(2):149-54.

35. Damodaran A, Malathi A, Patil N, Shah N, Marathe S. Therapeutic potential of yoga practices in modifying cardiovascular risk profile in middle aged men and women. J Assoc Physicians India. 2002;50(5):633-40.

Cite this article: Parikh S, Mahida P, Vaghela N, Shah H. Effect of Home Based Yoga on Blood Pressure and Quality of Life in Patients with Hypertension. Int J Clin Exp Physiol. 2021;8(1):26-30. 